\title{
EFEK STRATEGI PEMBELAJARAN DITINJAU DARI KEMAMPUAN AWAL MATEMATIKA TERHADAP HASIL BELAJAR MATEMATIKA KELAS XI IPS
}

\author{
Dewi Purwaningrum, dan Sumardi \\ Magister Administrasi Pendidikan Sekolah Pascasarjana UMS \\ dewi_purwaningrum@yahoo.com
}

\begin{abstract}
ABSTRAK
Penelitian ini bertujuan untuk menganalisis: (1) pengaruh strategi pembelajaran STAD dan strategi pembelajaran TPS terhadap hasil belajar matematika, (2) pengaruh kemampuan awal matematika terhadap hasil belajar matematika, (3) interaksi strategi pembelajaran dan kemampuan awal matematika terhadap hasil belajar matematika. Penelitian ini berjenis kuantitatif dengan desain quasi eksperiment. Populasi penelitian siswa kelas XI IPS SMAN 2 Sukoharjo tahun 2015/2016. Sampel penelitian ialah XI IPS 1 sebagai kelas eksperimen menggunakan strategi pembelajaran STAD dan XI IPS 3 sebagai kelas kontrol menggunakan strategi pembelajaran TPS. Pengambilan sampel dilakukan dengan teknik cluster random sampling. Metode pengumpulan data menggunakan tes dan dokumentasi. Teknik analisis data dengan analisis variansi dua jalan sel tak sama, sebelumnya dilakukan uji prasyarat normalitas dan homogenitas. Hasil penelitian pada $\alpha=5 \%$, (1) ada pengaruh strategi pembelajaran STAD dan TPS terhadap hasil belajar matematika; (2) ada pengaruh kemampuan awal matematika terhadap hasil belajar matematika; (3) ada interaksi strategi pembelajaran dan kemampuan awal matematika terhadap hasil belajar matematika.
\end{abstract}

Kata kunci: hasil belajar matematika, kemampuan awal matematika, STAD, TPS

\begin{abstract}
This research aims to test: (1) The effect of STAD learning strategy and TPS learning strategy on learning outcomes in mathematics, (2) The effect of early math abilities on learning outcomes in mathematics, (3) interaction between learning strategy and early math abilities on learning outcomes in mathematics. The type of research is quantitative approach with quasi experimental design. The population of this research were students of XI grade with IPS department at SMAN 2 Sukoharjo in 2015/2016 academic year. The research samples are XI IPS 1 as a experiments class using STAD learning strategy and XI IPS 3 as a control class using TPS learning strategy. Samples taken by cluster random sampling. Data collection method used is the test and documentation. The analysis technique used is two-way analysis of variance test different cells, previously performed using methods normality test and homogeneity test. Based on the research result with $\alpha=5 \%$ : (1) there are effect of STAD learning strategy and TPS learning strategy on learning outcomes in mathematics; (2) there
\end{abstract}


are effect of early math abilities on learning outcomes in mathematics; (3) there are interaction between learning strategy and early math abilities on learning outcomes in mathematics.

Keywords: early math abilities, learning outcomes in mathematics, STAD, TPS

\section{PENDAHULUAN}

Pendidikan matematika memegang peranan penting dalam perkembangan pendidikan. Namun, hasil belajar matematika di Indonesia masih rendah. Hal ini dikarenakan matematika menjadi momok yang menakutkan bagi mayoritas siswa. Hal ini dibuktikan dengan data survei TIMSS yang dilakukan oleh The International Association for the Evaluation and Educational Achievement (IAE) yang berkedudukan di Amsterdam, menempatkan Indonesia pada posisi ke 36 dari 40 negara pada tahun 2011 (Budi Murtiyasa, 2015: 1).

Rendahnya pencapaian hasil belajar juga terjadi pada materi Turunan Fungsi. Hal ini ditandai dengan adanya 60\%-75\% siswa SMA Negeri 2 Sukoharjo yang memperoleh nilai ulangan harian di bawah Kriteria Ketuntasan minimum (KKM) 75. Kesenjangan yang terdapat di lapangan ialah guru dalam mengajar cenderung kurang memperhatikan kemampuan awal siswa. Selain itu, guru matematika tidak melakukan pengajaran bermakna secara maksimal yang berakibat pola belajar siswa cenderung menghafal.

Kemampuan awal siswa adalah kemampuan yang telah dipunyai siswa sebelum ia mengikuti pembelajaran. Kemampuan awal dalam mata pelajaran matematika penting untuk diketahui guru sebelum memulai pembelajaran. Hal ini berguna untuk mengetahui apakah siswa mempunyai pengetahuan prasyarat (prerequisite) untuk mengikuti pembelajaran dan sejauh mana siswa telah mengetahui materi yang akan disajikan, sehingga guru dapat merancang pembelajaran lebih baik.

Pembelajaran yang baik dan bermakna harus bisa dilakukan oleh seorang guru khususnya guru matematika. Hal ini dapat dilakukan dengan cara pemilihan strategi pembelajaran yang sesuai dengan kemampuan yang dimiliki siswa. Strategi pembelajaran yang dimaksud ialah strategi pembelajaran Students Teams Achievement Division (STAD) dan Think Pair Share (TPS).

John A. Nunnary dkk (2013: 13) menyatakan bahwa STAD-Math is a structured cooperative learning program in which students work in 4-5 member heterogeneous teams to help each other solve problems and build mathematical understanding. Hal ini berarti strategi pembelajaran STAD merupakan strategi pembelajaran dimana siswa belajar dalam kelompok, berdiskusi menyelesaikan permasalahan, membangun pemahaman dan penghargaan yang diterima kelompok atas kerja keras mereka. Salah satu keunggulan STAD ialah interaksi yang terjadi di antara siswa dan guru yang berdampak pada kemampuan dalam berpendapat (Aris Shoimin, 2014: 189). Selain itu, penghargaan yang diberikan kepada kelompok terbaik juga menjadi tindakan yang menyenangkan untuk siswa.

Adekunle Oladipupo Bamiro (2015: 2) berpendapat bahwa Think Pair Share is a cooperative learning strategy that includes three components, namely, times for thinking, time for sharing with a partner, and time to share among pairs to a larger group. Ketiga tahap 
tersebut merupakan faktor penting dalam strategi pembelajaran TPS. Salah satu keunggulan strategi pembelajaran TPS ialah siswa dapat mengembangkan pengetahuan yang lebih dalam pada suatu topik (Anitha H. M. dan Anusha N. Rao, 2014: 464).

Merujuk pada hasil penelitian Adeneye Olarewaju Adeleye Awofala et al. (2012) yang berkaitan dengan penghargaan di dalam pembelajaran kooperatif menyimpulkan di antaranya bahwa STAD/TGT cooperative learning variants are used in mathematics instruction, there is that high possibility that the students would perform better at both the comprehension and application levels of cognition than at knowledge level of cognition. Hasil penelitian Mahmud Alpusari dan Riki Apriyandi Putra (2015) yang berkaitan dengan aplikasi Think Pair Share (TPS) menyimpulkan bahwa application of cooperative learning model TPS can improve students'science process skill overall. Hasil penelitian para ahli tesebut belum memberikan alternatif solusi pada penelitian ini. Oleh karena itu, penelitian ini berbeda dengan penelitian yang telah dilakukan sebelumnya.

Berdasarkan uraian tersebut dapat diajukan tiga hipotesis. (1) Ada pengaruh strategi pembelajaran STAD dan TPS terhadap hasil belajar matematika siswa SMA. (2) Ada pengaruh kemampuan awal matematika terhadap hasil belajar matematika siswa SMA pada materi Turunan Fungsi. (3) Ada interaksi antara strategi pembelajaran dan kemampuan awal matematika terhadap hasil belajar matematika siswa SMA pada materi Turunan Fungsi.

Penelitian ini ada tiga tujuan. (1) Menguji pengaruh strategi pembelajaran STAD dan TPS terhadap hasil belajar matematika siswa SMA. (2) Menguji pengaruh kemampuan awal matematika terhadap hasil belajar matematika siswa SMA pada materi Turunan Fungsi. (3) Menguji interaksi antara strategi pembelajaran dan kemampuan awal matematika terhadap hasil belajar matematika siswa SMA pada materi Turunan Fungsi.

\section{METODE}

Jenis penelitian dalam penelitian ini adalah penelitian eksperimen. Menurut Sutama (2015: 53) penelitian eksperimen adalah penelitian yang berupaya untuk meneliti dan menemukan pengaruh variabel tertentu terhadap variabel lainnya dalam kondisi yang sengaja dikontrol, dibuat konstan. Desain penelitian ini ialah kuasi-eksperimental. Tempat penelitian yaitu SMAN 2 Sukoharjo selama 7 bulan yaitu pada bulan Januari hingga bulan Juli 2016.

Populasi dalam penelitian ini adalah seluruh siswa kelas XI IPS tahun 2015/2016 dengan sampel XI IPS 1 sebagai kelas eksperimen menggunakan strategi pembelajaran STAD dan XI IPS 3 sebagai kelas kontrol menggunakan strategi pembelajaran TPS. Teknik sampling dilakukan dengan teknik cluster random sampling. Teknik pengumpulan data menggunakan metode tes dan dokumentasi. Metode tes digunakan untuk mengukur hasil belajar matematika dan kemampuan awal matematika, sedangkan metode dokumentasi digunakan untuk mengumpulkan data tentang nilai ujian nasional tahun pelajaran 2014/2015, sebagai dasar dalam mengadakan penelitian.

Teknik analisis data menggunakan analisis variansi dua jalan dengan sel tidak sama. Sebelum uji analisis variansi dua jalan, dilakukan uji normalitas dan uji homogenitas sebagai prasyarat analisis variansi (anava). Apabila hipotesis nol pada uji anava ditolak maka dilanjutkan dengan uji komparasi ganda. 


\section{HASIL DAN PEMBAHASAN}

Pembelajaran kelas eksperimen menggunakan strategi STAD dimulai dengan menyampaikan tujuan pembelajaran, mengkomunikasikan kompetensi dasar yang akan dicapai serta memotivasi tentang materi yang akan diajarkan pada siswa. Motivasi sangat diperlukan selama pembelajaran. Idha Novianti (2013: 273) menyatakan motivasi membuat siswa ingin belajar sehingga mereka dapat fokus dalam pembelajaran dan akhirnya hasil belajar dapat optimal.

Setelah itu guru menyajikan sedikit materi yang akan dipelajari. Materi tersebut sebagai berikut.

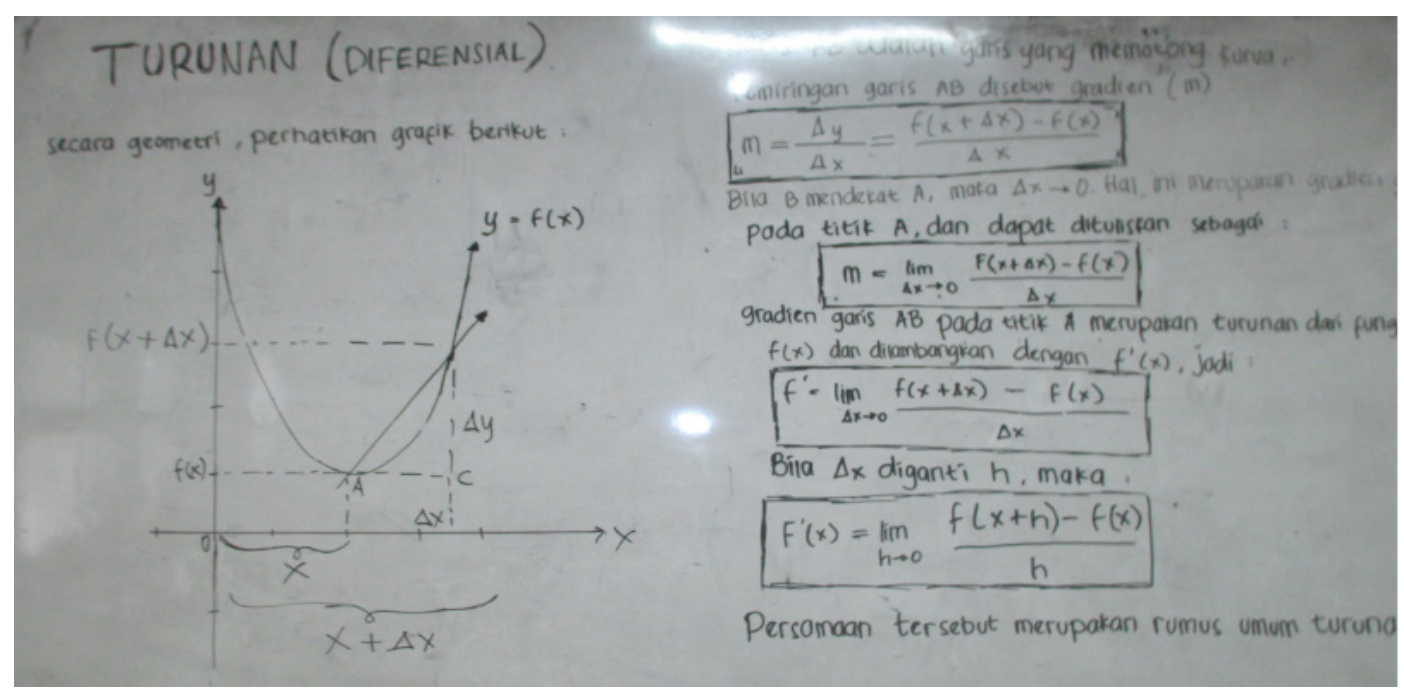

Gambar 1. Materi Awal Pembelajaran

Selanjutnya guru membentuk kelompok heterogen beranggotakan 4 siswa berdasarkan kemampuan awal matematika. Rina Dyah Rahmawati dan Ali Mahmudi (2014: 105) mengatakan bahwa fungsi utama dari berkelompok ialah memastikan semua anggota kelompok benar-benar belajar. Hal ini berdampak semua siswa dapat menguasai materi yang sedang dipelajari. Kemudian guru memberikan tugas pada semua kelompok. Berikut tugas yang diberikan guru.

Tentukan turunan dari fungsi $f(x)=x^{2}+3$

Gambar 2. Tugas Kelompok STAD

Pemberian tugas berfungsi sebagai permasalahan yang harus diselesaikan oleh semua anggota kelompok. Semua anggota kelompok bekerja sama dan bertukar pikiran menemukan jawaban dari permasalahan yang diberikan sehingga timbul interaksi di dalam kelompok. Hal ini sesuai dengan pendapat Diana Muslichatun dkk (2016: 106) bahwa STAD menekankan pada aktivitas dan interaksi di dalam kelompok untuk saling memotivasi dan saling membantu dalam penguasaan materi sehingga pencapaian prestasi dapat maksimal. Berikut merupakan jawaban dari tugas yang diberikan. 


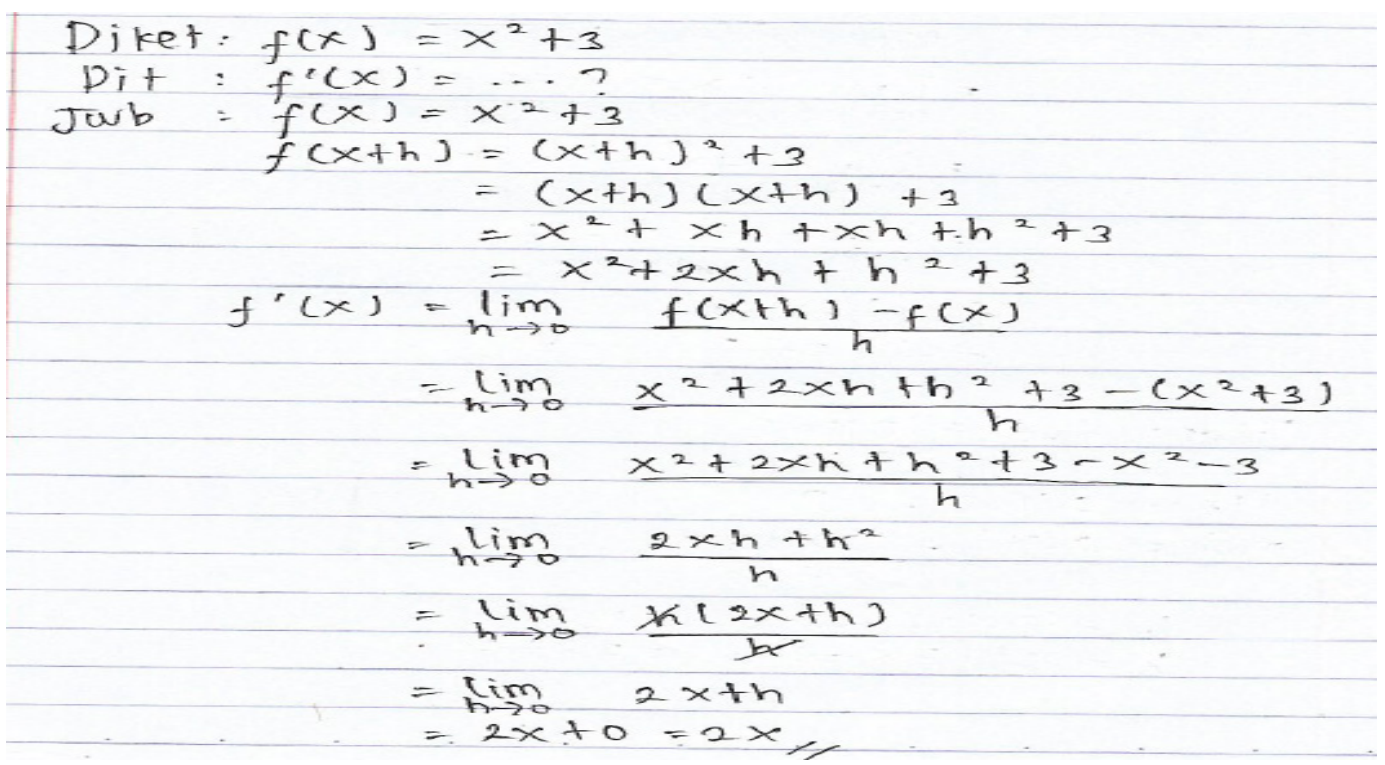

Gambar 3. Penyelesaian Kelompok STAD

Siswa yang dapat menyelesaikan permasalahan tersebut menjelaskan kepada temannya sehingga semua anggota dalam kelompok paham dan mengerti tentang materi yang dipelajarinya. Guru tetap memotivasi siswa agar berani menunjukkan kemampuannya dalam mengkomunikasikan hasil diskusi kelompok.

Pada saat presentasi, anggota kelompok mempunyai peran masing-masing. Hal ini sesuai dengan manfaat STAD bahwa siswa diajarkan berkomitmen untuk pengembangan kelompok serta menghargai dan saling percaya terhadap teman satu kelompok (Imas Kurniasih dan Berlin Sani, 2014: 22). Walaupun demikian, anggota kelompok tetap bertanggung jawab dalam keberhasilan anggota kelompoknya. Hal ini diperkuat pendapat Rahmatun Nisa dkk (2014: 24) bahwa kegagalan dan keberhasilan kelompok merupakan tanggung jawab setiap anggota kelompok. Selanjutnya guru memberikan kuis. Hal ini bertujuan untuk mengetahui kemampuan siswa setelah proses pembelajaran. Berikut soal kuis yang harus diselesaikan siswa.

$$
\begin{aligned}
& \text { Suatu proyek dapat dikerjakan selama } \mathrm{p} \text { hari dengan biaya tetap setiap harinya. } \\
& \left(4 p+\frac{100}{p}-40\right) \text { juta rupiah }
\end{aligned}
$$

Agar biaya proyek minimun, berapa hari proyek tersebut harus diselesaikan ? 
Kuis dikerjakan secara individu. Berikut penyelesaian soal kuis oleh siswa.

$\begin{aligned} & \text { Misal suatu proyek }=p(x) \\ & P(x)=p\left(4 p+\frac{100}{p}-40\right) \\ &=4 p^{2}+100-40 p \\ & P^{\prime}(x)=8 p-40=0 \\ & 8 p=40 \\ & P=5 \\ & \therefore \text { proyek tsh harus diselesaikan dalam waktu } 5 \text { hari }\end{aligned}$

Gambar 5. Penyelesaian Soal Kuis STAD

Siswa dilarang saling membantu meskipun dengan teman satu kelompoknya pada saat mengerjakan kuis. Rina Dyah Rahmawati dan Ali Mahmudi (2014: 105) mengatakan bahwa pada saat pengerjaan kuis, setiap siswa mempunyai tanggung jawab masing-masing untuk menguasai materi. Selanjutnya guru memberikan skor terhadap kuis tersebut dan menjumlahkan dengan skor siswa satu kelompoknya. Kelompok yang memiliki skor tertinggi mendapatkan penghargaan seperti aplause, ucapan selamat, dan hadiah. Pada pertemuan terakhir, guru memberikan penghargaan berupa hadiah untuk tiga kelompok terbaik. Ibrahim dan Nur Hidayati (2014: 123) menyatakan bahwa penghargaan yang diberikan dapat menyenangkan siswa atas prestasi yang telah mereka buat.

Pembelajaran pada kelas kontrol menggunakan strategi pembelajaran TPS dimulai dengan memberikan pertanyaan kepada siswa. Berikut pertanyaan yang diberikan oleh guru.

$$
\text { Tentukan turuman dari fungsi } f(x)=x^{2}+3
$$

Gambar 6. Permasalahan pada TPS

Siswa dituntut untuk berpikir (think) menemukan jawaban secara individu dari pertanyaan tersebut. Pada tahap ini siswa diberikan waktu untuk merumuskan jawaban pertanyaan yang diberikan. Dalam hal ini siswa harus memiliki keterampilan berpikir yaitu mengenal masalah, menemukan cara menyelesaikan permasalahan, mengumpulkan dan menyusun informasi yang diperlukan, memahami dan menggunakan bahasa yang tepat dan jelas, menganalisis data, menarik kesimpulan (L. Surayya dkk, 2014: 4). Berikut ini merupakan jawaban dari siswa. 


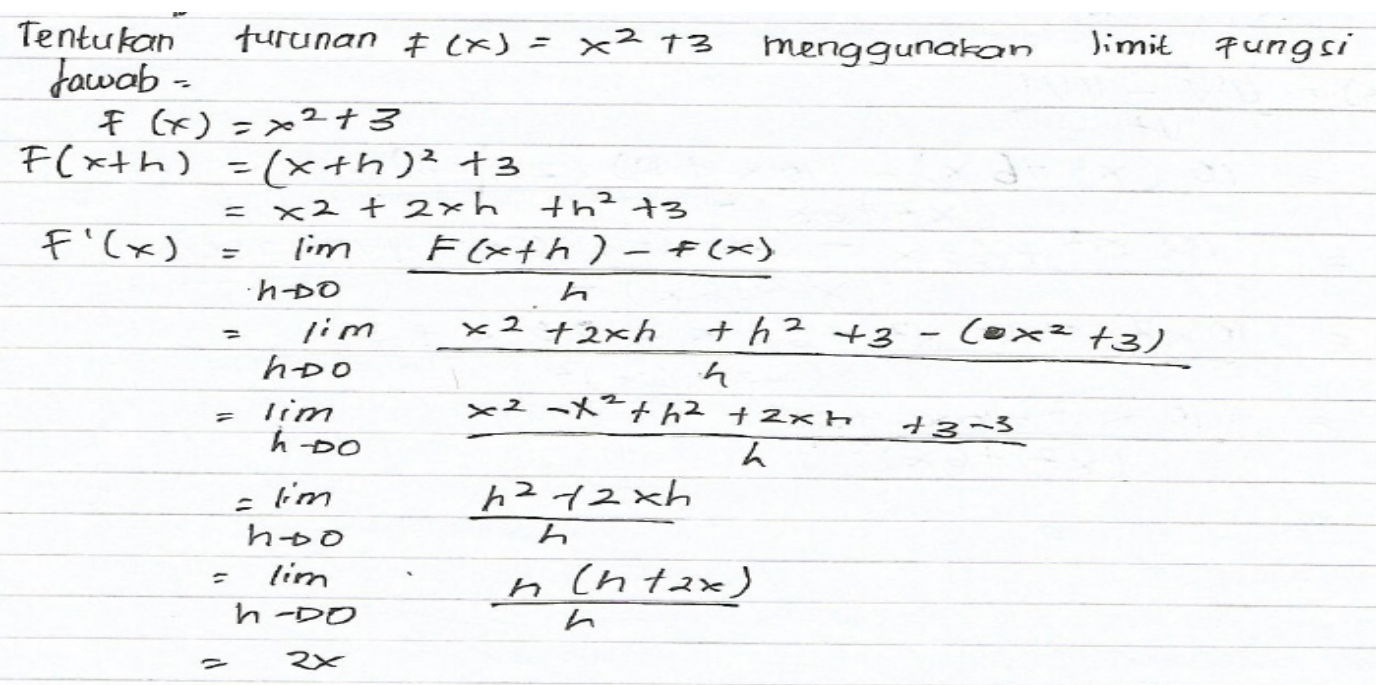

Gambar 7. Hasil berpikir Siswa

Penyelesaian pertanyaan secara individu bertujuan agar siswa menemukan konsep matematika dengan langkah yang mereka temukan sendiri. Hal ini sesuai dengan pendapat Anitha H. M dan Anusha N Rao (2014: 464) mengenai keunggulan TPS yaitu helps to develop in-depth knowledge of the topic.

Selanjutnya guru meminta siswa membentuk kelompok secara berpasangan (pair) dan meminta kelompok tersebut menyelesaikan masalah yang telah diselesaikan secara individu. Berikut hasil dari diskusi kelompok.

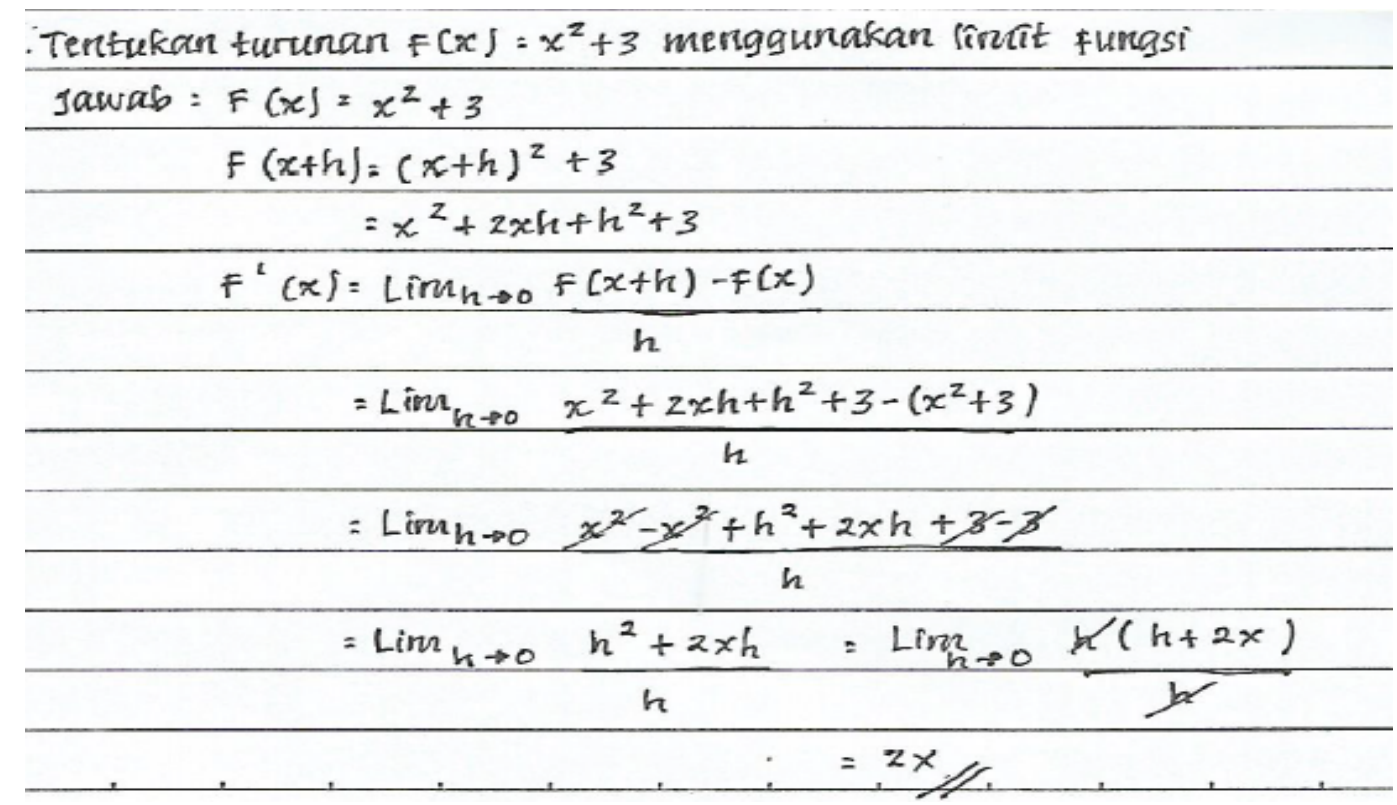

Gambar 8. Hasil diskusi Siswa

Dalam berdiskusi, siswa saling menyampaikan ide dan pendapat tentang jawaban dari permasalahan yang diberikan. Siswa dituntut aktif dalam proses pembelajaran sehingga terjadi interaksi dan kerja sama dalam kelompok tersebut. Anitha H. M dan Anusha N Rao (2014: 464) menyatakan salah satu keunggulan TPS ialah students are actively involved in 
the class. Selanjutnya tiap kelompok berbagi hasil diskusi dengan berkeliling ke pasangan lain. Hal ini bertujuan agar siswa berani mengemukakan pendapatnya dan terjadi komunikasi serta interaksi antar siswa dengan kelas maupun gurunya. Langkah terakhir ialah guru mengarahkan pembicaraan pada pokok permasalahan, menambah dan memperjelas materi yang belum diungkap siswa.

Tabel 1. Rangkuman Analisis Variansi Dua Jalan

\begin{tabular}{lccccc}
\hline \multicolumn{1}{c}{ Sumber } & JK & Dk & RK & $\mathbf{F}_{\text {obs }}$ & $\mathbf{F}_{\boldsymbol{\alpha}}$ \\
\hline Strategi Pembelajaran (A) & 798,967283 & 1 & 798,9673 & 8,627538 & 4,003983 \\
Kemampuan Awal & 2650,24274 & 2 & 1325,121 & 14,30914 & 3,153123 \\
Matematika (B) & 620,889634 & 2 & 310,4448 & 3,352296 & 3,153123 \\
Interaksi (AB) & 5463,79149 & 59 & 92,60664 & - & - \\
Galat & 9533,89114 & 64 & - & - & - \\
Total & & & & \\
\hline
\end{tabular}

Sumber: data diolah 2016

Hasil uji hipotesis pertama dengan $\alpha=5 \%$ memutuskan bahwa ada pengaruh strategi pembelajaran STAD dan strategi pembelajaran TPS terhadap hasil belajar matematika sehingga perlu dilakukan uji lanjut. Oleh karena strategi pembelajaran hanya memiliki dua faktor maka tidak diperlukan uji komparasi antar baris melainkan hanya melihat rerata marginalnya.

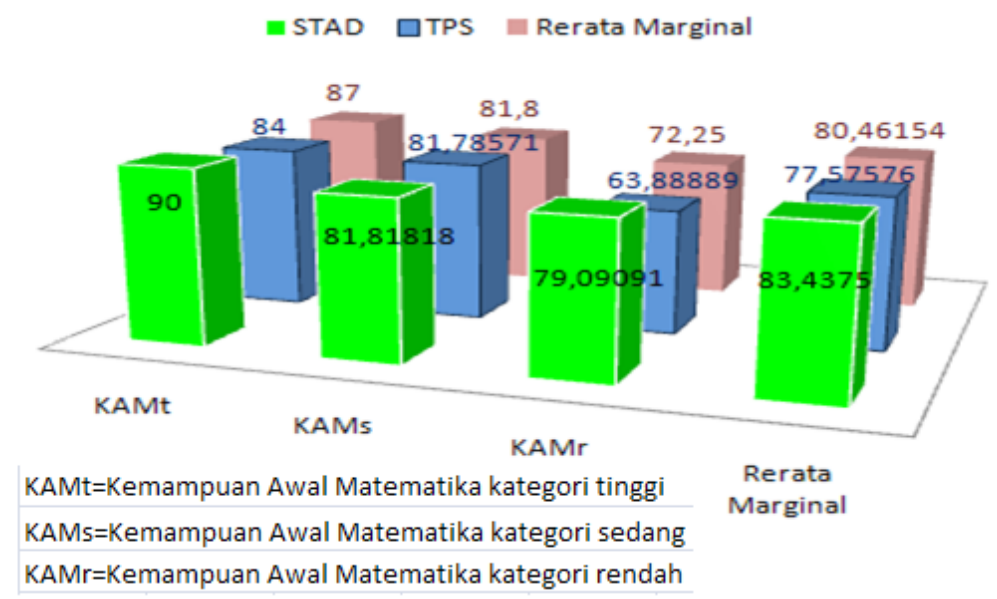

Gambar 9. Rerata Hasil Belajar Matematika Ditinjau dari Kemampuan AwalMatematika

Gambar 9 menunjukkan rerata margina STAD lebih tinggi dibanding rerata marginal TPS. Hal ini berarti strategi pembelajaran STAD lebih baik dari pada strategi pembelajaran TPS. Hasil ini sesuai dengan penelitian Wong Nguok Ling et. al. (2016) yang menyimpulkan STAD mendorong siswa dan guru untuk berinovasi dan kreatif dalam kegiatan belajar mengajar matematika di dalam kelas. Hal ini bermakna bahwa penerapan strategi pembelajaran 
STAD menyebabkan proses pembelajaran lebih inovatif dan kreatif sehingga siswa dapat meningkatkan kemampuannya berdampak pada hasil belajar matematika yang lebih baik.

Penerapan strategi pembelajaran STAD berdampak pada hasil belajar rmatematika lebih baik. Hal ini disebabkan jumlah siswa dalam kelompok pembelajaran STAD lebih banyak dibandingkan anggota kelompok strategi TPS yang hanya berpasangan. Dengan semakin banyaknya anggota dalam kelompok maka pendapat yang dikemukakan lebih bervariasi sehingga terjadi perpaduan pendapat yang lebih baik dibandingkan jika hanya berpasangan. Oleh karena itu, dapat disimpulkan strategi pembelajaran STAD berpengaruh terhadap hasil belajar matematika.

Hasil uji hipotesis kedua menyatakan ada pengaruh kemampuan awal matematika terhadap hasil belajar matematika dengan $\alpha=5 \%$. Oleh karena itu, sehingga perlu dilakukan uji lanjut.

Tabel 2. Komparasi Rerata Antar Kolom

\begin{tabular}{lcll}
\hline & Hasil & DK & \multicolumn{1}{c}{ Keputusan } \\
\hline $\mathrm{F}_{.1-2 .}$ & 3,244308 & 6,306247 & $\mathrm{H}_{0}$ tidak ditolak \\
$\mathrm{F}_{.1-3}$ & 23,49319 & 6,306247 & $\mathrm{H}_{0}$ ditolak \\
$\mathrm{F}_{.2-3}$ & 10,94264 & 6,306247 & $\mathrm{H}_{0}$ ditolak \\
\hline
\end{tabular}

Sumber: data diolah 2016

Tabel 2 menyatakan bahwa rerata yang diperoleh KAMt tidak jauh berbeda dengan rerata yang diperoleh KAMs. Oleh karena itu, karakteristik antara KAMt dan KAMs sama dengan karaktersitik rerata marginal KAM. Gambar 9 menunjukkan rerata marginal hasil belajar matematika pada KAMt lebih tinggi dibanding rerata marginal hasil belajar matematika KAMs. Hal ini berarti hasil belajar matematika ditinjau dari KAMt lebih baik dari pada hasil belajar matematika ditinjau dari KAMs. Dengan pemikiran yang sama hasil belajar matematika ditinjau dari KAMt lebih baik dari pada hasil belajar matematika ditinjau dari KAMr dan hasil belajar matematika ditinjau dari KAMs lebih baik dari pada hasil belajar matematika ditinjau dari KAMr.

Hasil penelitian tersebut sesuai dengan hasil penelitian Ibrahim dan Hidayati (2014) yang menyimpulkan bahwa perbedaan kemampuan awal matematika siswa tidak memberikan pengaruh yang signifikan terhadap peningkatan kemampuan pemecahan masalah matematika siswa yang memperoleh pembelajaran kooperatif tipe TGT. Hal ini bermakna bahwa kemampuan awal matematika yang dimiliki siswa menyebabkan hasil belajar matematika yang tidak terprediksi. Siswa yang memiliki kemampuan awal matematika kategori tinggi mendapatkan hasil belajar matematika yang lebih baik daripada siswa dengan kemampuan awal kategori sedang. Oleh karena itu dapat disimpulkan kemampuan awal matematika berpengaruh terhadap hasil belajar matematika.

Hasil uji hipotesis ketiga dengan $\alpha=5 \%$ memutuskan ada pengaruh strategi pembelajaran STAD dan strategi pembelajaran TPS terhadap hasil belajar matematika ditinjau dari kemampuan awal matematika sehingga perlu dilakukan uji lanjut. 
Tabel 3. Komparasi Rerata Antar Sel pada Kolom yang Sama

\begin{tabular}{lccc}
\hline & Hasil & DK & Keputusan \\
\hline $\mathrm{F}_{11-21}$ & 1,943705 & 11,85488 & $\mathrm{H}_{0}$ tidak ditolak \\
\hline $\mathrm{F}_{12-22}$ & 0,0000701 & 11,85488 & $\mathrm{H}_{0}$ tidak ditolak \\
\hline $\mathrm{F}_{13-23}$ & 12,35281 & 11,85488 & $\mathrm{H}_{0}$ ditolak \\
\hline
\end{tabular}

Sumber: data diolah 2016

Hasil uji komparasi rerata antar strategi pembelajaran (SP) ditinjau dari KAMt menyatakan tidak ada SP yang mempunyai perbedaan rerata yang signifikan sehingga dapat berpengaruh terhadap hasil belajar matematika. Hal ini berarti karakteristik antara STAD dan TPS untuk KAMt sama dengan karaktersitik rerata marginal SP. Gambar 9 menyatakan rerata marginal STAD lebih tinggi dibanding rerata marginal TPS. Hal ini berarti strategi pembelajaran STAD lebih baik dari pada TPS. Dengan pemikiran yang sama, pada KAMs strategi pembelajaran STAD lebih baik dari pada TPS. Hal ini juga berlaku pada KAMr.

Hasil ini sesuai dengan hasil penelitian Tuna Gencosman dan Mustafa Dogru (2012) menyimpulkan educational based on STAD techniques has a higher effect on the selfefficacy perceptions, academic achievement and reducing test anxiety of students. Hal ini bermakna bahwa penggunaan strategi pembelajaran STAD kepada siswa dapat meningkatkan hasil belajar matematika. Oleh kerena itu, pada kemampuan awal matematika, hasil belajar matematika dengan menerapakan strategi pembelajaran STAD lebih baik dari pada hasil belajar matematika dengan menerapakan strategi pembelajaran TPS.

Tabel 4. Komparasi Rerata Antar Sel pada Baris yang Sama

\begin{tabular}{lccl}
\hline & Hasil & DK & \multicolumn{1}{c}{ Keputusan } \\
\hline $\mathrm{F}_{11-12}$ & 3,786439 & 11,85488 & $\mathrm{H}_{0}$ tidak ditolak \\
$\mathrm{F}_{11-13}$ & 6,731447 & 11,85488 & $\mathrm{H}_{0}$ tidak ditolak \\
$\mathrm{F}_{12-13}$ & 0,441751 & 11,85488 & $\mathrm{H}_{0}$ tidak ditolak \\
$\mathrm{F}_{21-22}$ & 0,308846 & 11,85488 & $\mathrm{H}_{0}$ tidak ditolak \\
$\mathrm{F}_{21-23}$ & 20,68802 & 11,85488 & $\mathrm{H}_{0}$ ditolak \\
$\mathrm{F}_{22-23}$ & 18,94753 & 11,85488 & $\mathrm{H}_{0}$ ditolak \\
\hline
\end{tabular}

Sumber: data diolah 2016

Hasil uji komparasi rerata antara KAMt dan KAMs dengan menggunakan STAD memutuskan bahwa rerata yang diperoleh dari KAMt tidak berbeda jauh dengan rerata yang diperoleh KAMs. Hal ini berarti karakteristik antara KAMt dan KAMs sama dengan karakteristik rerata marginal KAM. Gambar 9 menyatakan rerata marginal KAMt lebih tinggi dibanding rerata marginal KAMs. Hal ini berarti KAMt lebih baik dari pada KAMs dengan menerapkan STAD. Dengan pemikiran yang sama KAMt lebih baik dari pada KAMr dan KAMs lebih baik dari pada KAMr.

Hasil ini sesuai dengan penelitian yang dilakukan Irawati (2014) yang menyimpulkan bahwa siswa berkemampuan awal tinggi memperoleh hasil belajar pemahaman dan hasil 
belajar tingkat tinggi yang lebih baik dibandingkan dengan siswa berkemampuan awal rendah. Hal ini bermakna bahwa siswa yang memiliki KAMt mendapatkan hasil belajar matematika yang lebih baik dibandingkan siswa dengan KAMs dan KAMr. Penerapan strategi pembelajaran STAD pada siswa dengan KAMt memiliki hasil belajar yang lebih baik dari siswa dengan KAMs dan KAMr pada kelas yang sama.

Hasil uji komparasi rerata antara KAMt dan KAMs dengan menggunakan TPS memutuskan bahwa rerata yang diperoleh dari KAMt tidak berbeda jauh dengan rerata yang diperoleh KAMs. Hal ini berarti karakteristik antara KAMt dan KAMs sama dengan karakteristik rerata marginal KAM. Gambar 9 menyatakan rerata marginal KAMt lebih tinggi dibanding rerata marginal KAMs. Hal ini berarti KAMt lebih baik dari pada KAMs dengan menggunakan TPS. Dengan pemikiran yang sama KAMt lebih baik dari pada KAMr dan KAMs lebih baik dari pada KAMr.

Hasil ini sesuai dengan penelitian yang dilakukan Anggraini dkk (2013) yang menyimpulkan bahwa ada hasil belajar yang signifikan antara kelompok siswa yang berkemampuan awal tinggi dan rendah. Hal ini bermakna bahwa kemampuan awal matematika yang dimiliki siswa memberikan pengaruh terhadap hasil belajar matematika. Oleh karena itu, pada strategi pembelajaran TPS, KAMt lebih baik dibanding KAMs dan KAMr terhadap hasil belajar matematika.

Penggunaan strategi pembelajaran STAD dan TPS pada siswa dengan KAMt berdampak pada hasil belajar matematika yang lebih baik dibanding siswa dengan KAMs dan KAMr. Oleh karena itu disimpulkan bahwa interaksi strategi pembelajaran dan kemampuan awal matematika berpengaruh terhadap hasil belajar matematika.

Faktor yang paling berpengaruh terhadap hasil belajar ialah kemampuan awal matematika yang dimiliki oleh siswa. Berdasarkan Tabel 1 selisih hasil perhitungan antara $\mathrm{F}_{\text {obs }}$ dan $\mathrm{F}_{\alpha}$ pada kemampuan awal matematika lebih besar dari pada selisih perhitungan variabel lainnya. Hal ini memperkuat bahwa dukungan kemampuan awal matematika yaitu kemampuan yang telah dimiliki siswa sebelum ia mengikuti pelajaran yang diberikan yang berfungsi sebagai pengungkapan kembali pengetahuan baru siswa serta keistimewaan STAD dan TPS sebagai pembelajaran kooperatif yang menekankan pada interaksi siswa dalam kelompok berdampak pada hasil belajar matematika yang lebih baik. Oleh karena itu, hasil belajar matematika yang diperoleh siswa selain dipengaruhi oleh strategi pembelajaran STAD dan strategi pembelajaran TPS serta kemampuan awal matematika juga dipengaruhi oleh interaksi di antara keduanya.

\section{SIMPULAN}

Strategi pembelajaran STAD dimulai dengan menyampaikan tujuan pembelajaran, mengkomunikasikan kompetensi dasar yang akan dicapai serta memotivasi tentang materi yang akan diajarkan siswa. Selanjutnya guru menyajikan sedikit materi yang akan dipelajari dan membentuk kelompok heterogen beranggotakan 4 siswa berdasarkan kemampuan awal matematika. Siswa saling bekerja sama dan berinteraksi memberikan tanggapan terhadap materi maupun tugas yang diberikan guru. Kemudian kelompok mengemukakan hasil diskusi di depan kelas agar terjadi pertukaran pendapat yang lebih luas dan interaksi antar kelas. Selanjutnya guru memberikan kuis untuk mengetahui apakah siswa telah menguasai materi yang sedang dipelajari yaitu tentang Turunan Fungsi dan dikerjakan secara individu. Skor 
siswa saat mengerjakan kuis dijumlahkan dengan skor teman dalam kelompoknya. Kelompok yang memiliki skor tertinggi mendapatkan penghargaan dari guru.

Strategi pembelajaran TPS dimulai dengan memberikan pertanyaan kepada siswa. Siswa berpikir (think) menemukan jawaban pertanyaan tersebut secara individu. Selanjutnya siswa membentuk kelompok secara berpasangan (pair) yang bertujuan agar siswa saling bertukar pendapat, bekerja sama dan terjadi interaksi di dalam kelompoknya. Kemudian tiap kelompok berbagi hasil diskusi dengan berkeliling ke kelompok lain, menyampaikan hasil diskusi kepada teman yang berbeda kelompok dengannya. Terakhir ialah guru mengarahkan pembicaraan pada pokok permasalahan dan memperjelas materi tentang Turunan Fungsi.

Berdasarkan hasil analisis dan pembahasan, dapat disimpulkan bahwa: (1) Pada $\alpha=5 \%$, ada pengaruh strategi pembelajaran STAD dan TPS terhadap hasil belajar matematika; (2) Pada $\alpha=5 \%$, ada pengaruh kemampuan awal matematika terhadap hasil belajar matematika; (3) Pada $\alpha=5 \%$, ada interaksi strategi pembelajaran dan kemampuan awal matematika terhadap hasil belajar matematika.

\section{DAFTAR PUSTAKA}

Alpusari, M., \& Putra, R. A. (2015) The application of cooperative learning think pair share (TPS) model to increase the process science skills in class IV elementry school number 81 Pekanbaru city. International Journal of Science and Research (IJSR), 4(4), 28052808. Diakses pada 8 April 2016, dari http://www.ijsr.net/archive/v4i4/SUB153806.pdf

Anggraini, V. D., Mukhadis, A., \& Muladi. (2013). Problem based learning, motivasi belajar, kemampuan awal, dan hasil belajar siswa SMK. Jurnal Ilmu Pendidikan, 19(2), 187195. Diakses pada 23 April 2016, dari http://journal.um.ac.id/index.php/jip/article/ download/4211/ 1198

Awofala, A. O. A., Fatade, A. O., \& Ola-Oluwa, S. A. (2012). Achievement in cooperative versus individualistic goal-structured junior secondary school mathematics classrooms in Nigeria. International Journal of Mathematics trends and Technology, 3(1), 7-12. Diakses pada 19 Mei 2016, dari http://www.ijmttjournal.org/Volume-3/issue-1/IJMTTV3I1P502.pdf

Bamiro, A. O. (2015). Effects of guided discovery and think-pair-share strategies on secondary school students' achievement in chemistry. SAGE Open, 1-7. Diakses pada 19 Mei 2016, dari http://sgo.sagepub.com/content/spsgo/5/1/ 2158244014564754.full.pdf

Gencosman, T., \& Dogru, M., (2012). Effect of student teams-achievement divisions technique used in science and technology education on self-efficacy, test anxiety and academic achievement. Journal of Baltic Science Education, 11(1), 43-54. Diakses pada 19 Mei 2016, dari http://oaji.net/ articles/2014/987-1419166833.pdf

Ibrahim., \& Hidayati, N. (2014). Pengaruh model pembelajaran teams games tournament (TGT) terhadap peningkatan kemampuan pemecahan masalah matematika ditinjau dari kemampuan awal siswa SMAN 1 Seyegan. Jurnal AgriSains, 5(2), 115-136. Diakses pada 25 Maret 2016, dari http://ejurnal.mercubuana-yogya.ac.id/index.php/Agrisains/ article/view/12 7/115

Irawati, R. K. (2014). Pengaruh model problem solving dan problem possing serta kemampuan awal terhadap hasil belajar siswa. Jurnal Pendidikan Sains, 2(4), 184-192. Diakses pada 23 April 2016, dari http://journal.um.ac.id/ index.php/jps/article/download/4534/998 
Kurniasih, I. \& Sani, B. (2014). Ragam Pengembangan Model Pembelajaran untuk Peningkatan Profesionalisme Guru. Surabaya: Kata Pena

Ling, W. N., Bin Ghazali, M. I., \& Raman, A. (2016). The effectiveness of student teamsachievement division (STAD) cooperative learning on mathematics achievement amonng school students in Sarikei District, Sarawak. International Journal of Advanced Research and Development, 1(3), 17-21. Diakses pada 19 Mei 2016, dari http://www. researchgate.net/ publication/298972734

M. Anitha, H., \& Rao, A. N. (2014). Active learning techniques in engineering education. International Journal of Research in Engineering and Technology, 3(11), 462-465. Diakses pada 7 April 2016, dari http://www. journals.indexcopernicus.com/issue. php?id $=12017 \&$ id_issue $=881054$

Murtiyasa, B. (2015). Tantangan pembelajaran matematika era global.Prosiding Seminar NasionalMatematikadanPendidikanMatematikaUMS(pp28)ISBN:978.602.361.002.0

Muslihatun, D., Saputro, S., \& Agustina, W. (2016). Efektivitas metode kooperatif tipe student teams achievement division (STAD) dan teams games tournament (TGT) berbantuan media peta konsep terhadap prestasi belajar ditinjau dari motivasi berprestasi pada materi stoikimetri.Jurnal Pendidikan Kimia, 5(1), 105-114. Diakses pada 8 Mei 2016, dari http://jurnal.fkip.uns.ac.id/index.php/kimia/issue/view/557

Nisa, R., Musdi, E., Jazwinarti. (2014). Penerapan pembelajaran kooperatif tipe think pair share pada pembelajaran matematika di kelas XI IPS SMA Negeri 2 Padang Panjang. Jurnal Pendidikan Matematika,3(1), 23-28. Diakses pada 15 April 2016, dari http:// ejournal.unp.ac.id/students/index. php/pmat/article/view/1215/907

Novianti, I. (2013). Experimentation cooperative learning student team achievement division (STAD) type viewed from learning motivation. Asian Journal of Education and e-Learning, 1(5), 272-276. Diakses pada 8 Mei 2016, dari http://www.ajouronline.com/ index.php?journal=AJEEL $\&$ page $=$ article $\&$ op $=$ view $\&$ path[] $=656$

Nunnery, J. A., Chappell, S., \& Arnold, P. (2013). A meta-analysis of a cooperative lerning model's effects on student achievement in mathematics. Cypriot Journal of Educational Sciences, 8(1), 34-48. Diakses pada 8 April 2016, dari http://www.world-educationcenter.org/ index.php/cjes/article/viewArticle/8.1.3

Rahmawati, R. D., Mahmudi,A. (2014). Keefektifan pembelajaran kooperatif stad dan tai ditinjau dari aktivitas dan prestasi belajar matematika siswa. Jurnal Prima Edukasia, 2(1), 102 - 115. Diakses pada 25 Maret 2016, dari http://journal.uny.ac.id/index.php/ jpe/article/view/2648/2202

Shoimin, A. (2014). 68 Model Pembelajaran Inovatif dalam Kurikulum 2013. Yogyakarta: Ar Ruzz Media

Surayya, L., Subagia, I. W., \& Tika, I. N. (2014). Pengaruh model pembelajaran think pair share terhadap hasil belajar IPA ditinjau dari keterampilan berpikir kritis siswa. E-Journal Program Pascasarjana Universitas Pendidikan Ganesha, 4, 1-11. Diakses pada 3 Februari 2016, dari http://pasca.undiksha.ac.id/e-journal/index.php/jurnal_ipa/ article/download 1105/853

Sutama. (2015). Metode Penelitian Pendidikan Kuantitatif, Kualitatif, PTK, $R \&$ D. Surakarta: Fairuz Media 